Document downloaded from:

http://hdl.handle.net/10251/84253

This paper must be cited as:

Torres Górriz, B.; Paya-Zaforteza, I.; Calderón García, PA.; Sales Maicas, S. (2017). New fiber optic sensor for monitoring temperatures in concrete structures during fires. Sensors and Actuators A: Physical. 254:116-125. doi:10.1016/j.sna.2016.12.013.

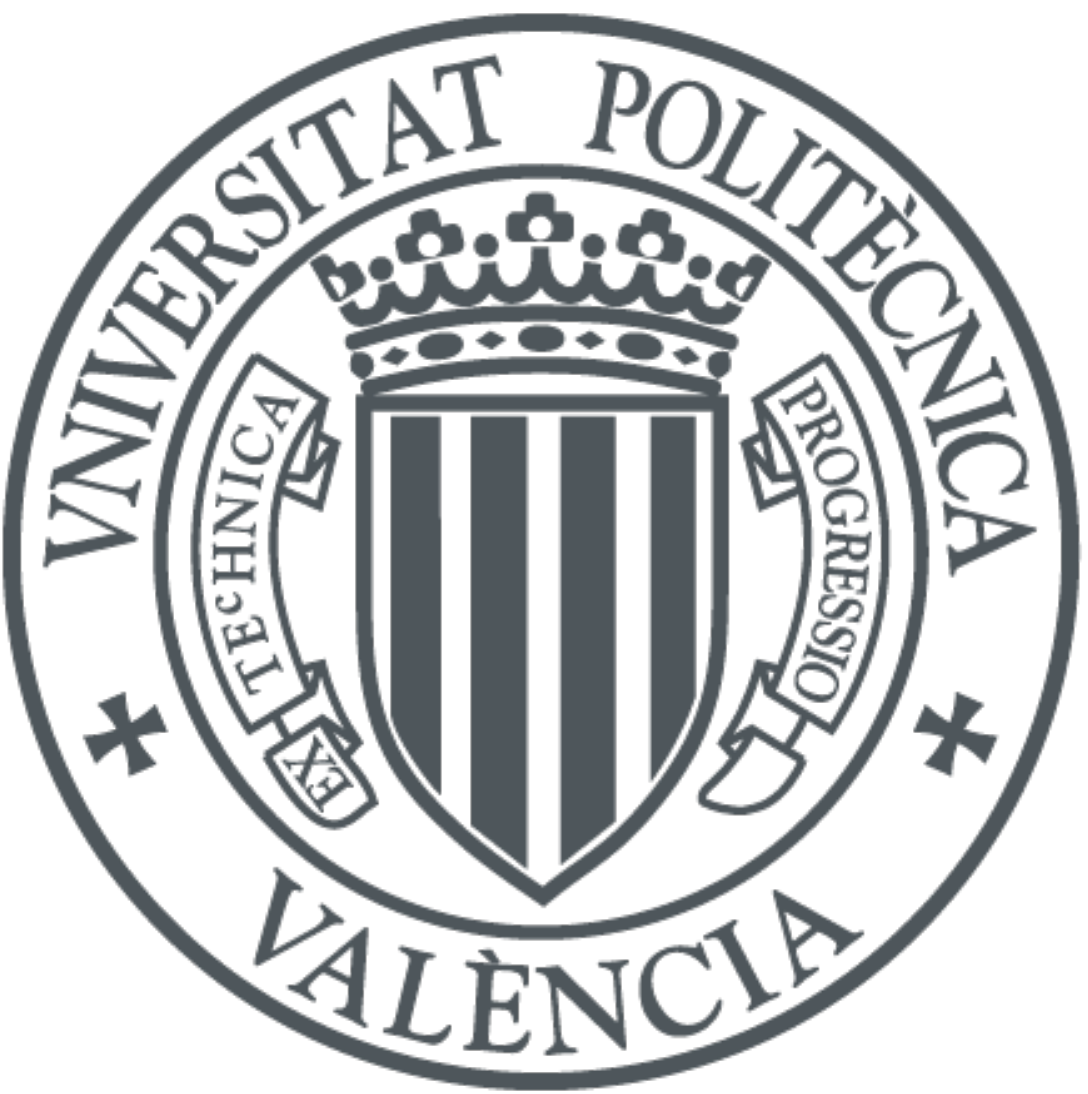

The final publication is available at

http://dx.doi.org/10.1016/j.sna.2016.12.013

Copyright Elsevier

Additional Information 
Torres-Gorriz B., Paya-Zaforteza, I., Calderon Garcia, P.A., Sales Maicas, S.

New fiber optic sensor for monitoring temperatures in concrete structures during fires

(2017) Sensors and Actuators, A: Physical, 254, pp. 116-125. DOI: 10.1016/j.sna.2016.12.013

Please cite this paper as:

Torres-Gorriz, B., Paya-Zaforteza, I., Calderon Garcia, P.A., Sales Maicas, S. New fiber optic sensor for monitoring temperatures in concrete structures during fires (2017) Sensors and Actuators, A: Physical, 254, pp. 116-125.

DOI: $10.1016 /$ j.sna.2016.12.013

\section{Highlights.}

A new fiber optic sensor for monitoring high temperatures is proposed.

The new sensor is based on the use of Regenerated Fiber Bragg Gratings.

Sensors were embedded in a loaded concrete beam and subjected to a fire test.

The maximum temperatures measured by the sensors were over $950^{\circ} \mathrm{C}$.

Sensor measurements were checked by numerical simulations and thermocouples.

New fiber optic sensor for monitoring temperatures in concrete structures during fires. 


\title{
New fiber optic sensor for monitoring temperatures in concrete structures during fires
}

\author{
Torres-Gorriz, B. ${ }^{1}$, Paya-Zaforteza, I. ${ }^{1}$, Calderon Garcia, P.A. ${ }^{1}$, Sales Maicas, S. ${ }^{2}$ \\ ${ }^{1}$ ICITECH, Universitat Politècnica de València, València Spain \\ ${ }^{1}$ ITEAM, Universitat Politècnica de València, València Spain
}

\begin{abstract}
.
Monitoring temperatures in structures during fires provides valuable information to 1) the firemen engaged in extinguishing it, 2) those who assess its security, and 3) the organizations who have to decide on its possible repair, renovation or demolition. Developing sensors able to measure extremely high temperatures in actual blaze conditions is therefore a fundamental requirement.

This paper proposes a new fiber optic sensor based on Regenerated Fiber Bragg Gratings specially designed to be embedded in concrete structures to monitor temperatures during fire events. A practical test was carried out on a $5.8 \mathrm{~m}$ long beam subjected to the ISO-834 fire curve for 77 minutes under the typical loads borne by beams in conventional structures. Nine optical sensors were installed at the mid-span section of the beam and were submitted directly to flames and high temperature gradients (of the order of $200^{\circ} \mathrm{C} / \mathrm{min}$ ) that make them measure maximum temperatures of $953^{\circ} \mathrm{C}$. The temperatures recorded by the new sensors were compared with those obtained from electrical sensors (thermocouples) and a numerical model, with which they showed a good fit, except in those places in which concrete spalling caused distortions in the results and/or failure of the sensors. The paper thus demonstrates the viability of optical technologies in monitoring reinforced concrete during fires and analyzes sensor behavior to point out areas in which additional research is required.
\end{abstract}

Keywords: Fire, High temperature measurement, Fiber optic sensor, Regenerated fiber Bragg grating, concrete structures. 


\section{Introduction}

Although concrete is recognized as a fire-resistant material in the construction industry, it also tends to get damaged when exposed to the high temperatures produced by fires [1]. For example, the concrete bridge that takes the Paramount Boulevard across the Pomona Freeway in Montebello, California, had to be demolished after a tanker truck caught fire under its deck on December 14, 2011 [2]. Another example of the vulnerability of concrete structures subjected to fires occurred in the Windsor Building in Madrid on February 12,2005 . This fire started on the $21^{\text {st }}$ floor and spread to all the other floors over the fifth. This building had reinforced concrete in its two-way floor slabs, central and interior columns and steel in its outer columns and in some composite beams. The building had to be demolished after the fire [3].

In this context, monitoring temperature evolution in a concrete structure is a key part of evaluating its security both during and after a fire $[4,5]$ since it provides information on the residual resistance of its materials. Temperatures are usually recorded by electric sensors such as thermocouples, which have been tested with satisfactory results (see e.g. [6-8]). However, as these sensors are electric, they cannot be used in places such as power plants, electrified railways or some biomedical applications, among others [6, 9].

Fiber optic sensors are an alternative to the electric type and have several advantages over them, such as flexibility, high precision and sensitivity [10,11]. They are also immune to electro-magnetic interference (EMI), which makes them especially suitable for cases in which thermocouples cannot be used. They are also multiplexable, which allows a large number of sensors to be connected to a single cable. This means monitoring networks can be designed for a simple wiring system which is therefore cheaper. All these properties make fiber optic sensors a good alternative to conventional sensors in structural health monitoring [12].

Fiber optic sensors have given satisfactory results in lab tests at high temperatures. For example, Barrera et al [13] tested regenerated multimode Bragg Grating-based sensors and calibrated the relation between temperature and wavelength up to $1100^{\circ} \mathrm{C}$. Habisreuther et al. [14] used fiber Bragg gratings inscribed into multimode single crystalline sapphire fibers, operating at up to $1900{ }^{\circ} \mathrm{C}$. Tu et al. [15] developed multilayer metal-coated regenerated grating sensors that were calibrated for maximum temperatures of $600{ }^{\circ} \mathrm{C}$. Canning [16] recently presented a review of regenerated fiber Bragg grating applications and studied the optimization of optical sensing and instrument technologies for harsh environments, such as those frequently found in the energy sector or in fire events. All these tests were conducted in electric furnaces under ideal lab conditions, very different from those found in a real fire. Only a few authors have carried out tests on structural elements in situations similar to those present in a real fire scenario: Bueno et al [17] tested Bragg Grating based sensors and regenerated Bragg Gratings embedded in small concrete specimens at up to $620^{\circ} \mathrm{C}$. Rinaudo et al. [4] installed three different types of regenerated Bragg Grating sensors on the surface of two concrete specimens at temperatures up to $970^{\circ} \mathrm{C}$. Rinaudo et al. [18] also installed Bragg Grating-based sensors on concrete-filled 
cylindrical steel columns subjected to a compression load in which the sensors measured maximum temperatures in the concrete of approximately $130^{\circ} \mathrm{C}$.

The above studies showed not only the viability of fiber-optic technology to monitor temperatures in structures subjected to fires but also the need to carry out new studies that would allow: 1) an in-depth study of fiber-optic sensor behavior under the conditions of an actual fire, 2) extend their operating range, and 3 ) the study of embedding sensors and wiring in concrete.

This paper thus proposes a new optic sensor to measure temperatures in concrete structures that was tested on a structural element in similar conditions to those of a real fire. We begin by explaining the fundamentals of high-temperature optic sensors and a description of the main characteristics of the sensor we propose. We then describe the testing of a number of sensors in a concrete beam subjected to typical loads and compare the temperatures measured by the sensor with those recorded by thermocouples and a finite element model. The comparison of the results and the analysis of the state of the optic sensors after the tests showed that they had operated correctly and allowed us to draw valuable conclusions on monitoring temperatures in concrete structures during fires.

\section{Operating principle of high-temperature fiber optic sensors}

Fiber Optic Sensors (henceforth FOS) detect variations in the properties of light travelling through the optical fiber. The fiber usually consists of three layers: the core, which is a thin glass fiber, the cladding that confines the propagation of the light within the fiber core, and an outer coating or jacket that provides the fiber's mechanical strength and protects it from damage and moisture absorption. There are several types of FOS, Fiber Bragg Grating (FBG) sensors being the most commonly used [19, 20]. FBGs can be used to measure high temperatures but standard FBGs lose stability and degrade significantly at temperatures close to $600{ }^{\circ} \mathrm{C}$, after which they become useless [4, 21-22]. One way to overcome this temperature limit is to use Regenerated Fiber Bragg Gratings (RFBGs) [13]. Below we explain the basics of FBG and RFBG sensors and the sensor proposed in this paper, which use RFBGs.

\subsection{Fiber Bragg Grating (FBG)}

A FBG is a reflector built in a short segment of the core of an optical fiber by exposing the fiber to an intense UV light. This exposure creates periodic alterations in the index of refraction of the fiber core, known as Bragg gratings, and makes the FBG (1) reflect only particular narrowband wavelengths of light known as Bragg wavelengths, and (2) transmit all others (Fig 1). The Bragg wavelength condition is given by Eq. (1), where $\lambda_{B}$ is the wavelength of the FBG, $n_{\text {eff }}$ is the effective refractive index of the fiber core, and $\Lambda$ is the Bragg grating period or distance between two consecutive alterations of the fiber core [23]. 


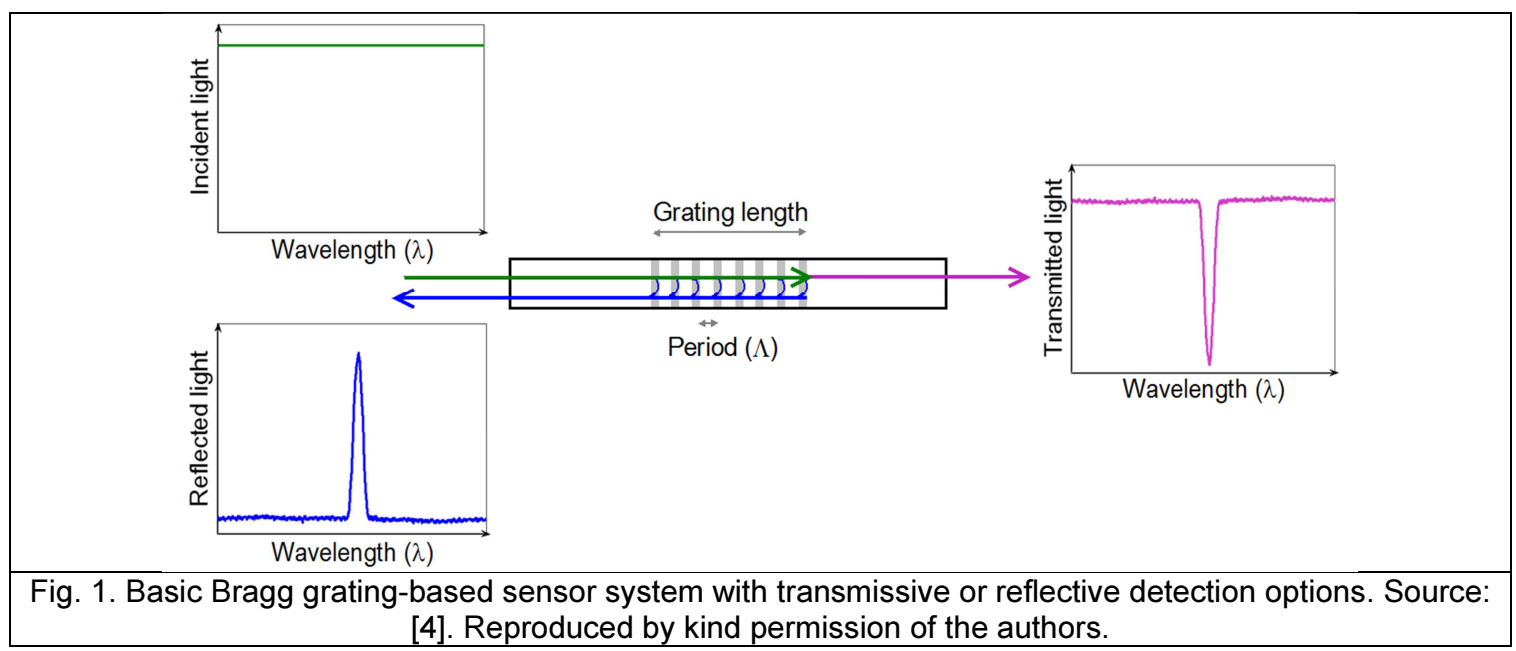

External perturbations can result in strain $(\varepsilon)$ and temperature $(T)$ changes that modify the Bragg grating period $\Lambda$ and also induce a shift $\Delta \lambda_{B}$ in the Bragg wavelength. This shift is given by Eq. (2) when only the dominant linear effects of $\varepsilon$ and $T$ on a FBG are considered and higher order cross-sensitivities are neglected (see [24, 25] for more details).

$\Delta \lambda_{B}=k_{\varepsilon} \Delta \varepsilon+k_{T} \Delta T$

In Eq. (2), $k_{\varepsilon}$ and $k_{T}$ are the coefficients of wavelength sensitivity to strain and temperature for an FBG. Their values were obtained experimentally for the presented sensor (not for an isolated FBG) as explained in section 2.3.

\subsection{Regenerated Fiber Bragg Grating (RFBG)}

Standard FBGs suffer from a serious limitation for high temperature measurements; the periodic grating created in the core of the optical fiber decays as a function of temperature and time, and as a result the grating amplitude is erased and the sensor becomes useless.

One way to overcome this temperature limit is to use Regenerated Fiber Bragg Gratings (RFBGs), which undergo physical and chemical processes that make them stable at high temperatures. RFBGs are created in three steps: first, the fiber is placed in a hydrogenation chamber at room temperature, then the FBG is inscribed into the hydrogen-loaded optical fiber by laser. Finally, the fibers are subjected to an annealing process inside a tubular furnace. During this phase, as the temperature increases, the original FBGs are progressively degraded until erasure and a new regenerated FBG (RFBG) is created (Fig. 2). As a consequence of their production process, RFBGs are extremely fragile and cannot be installed uncovered in a structural element, since the external loads and the harsh environment of a construction site would affect their durability and behavior. They are therefore protected by the packaging, this being a crucial element of the sensor. 


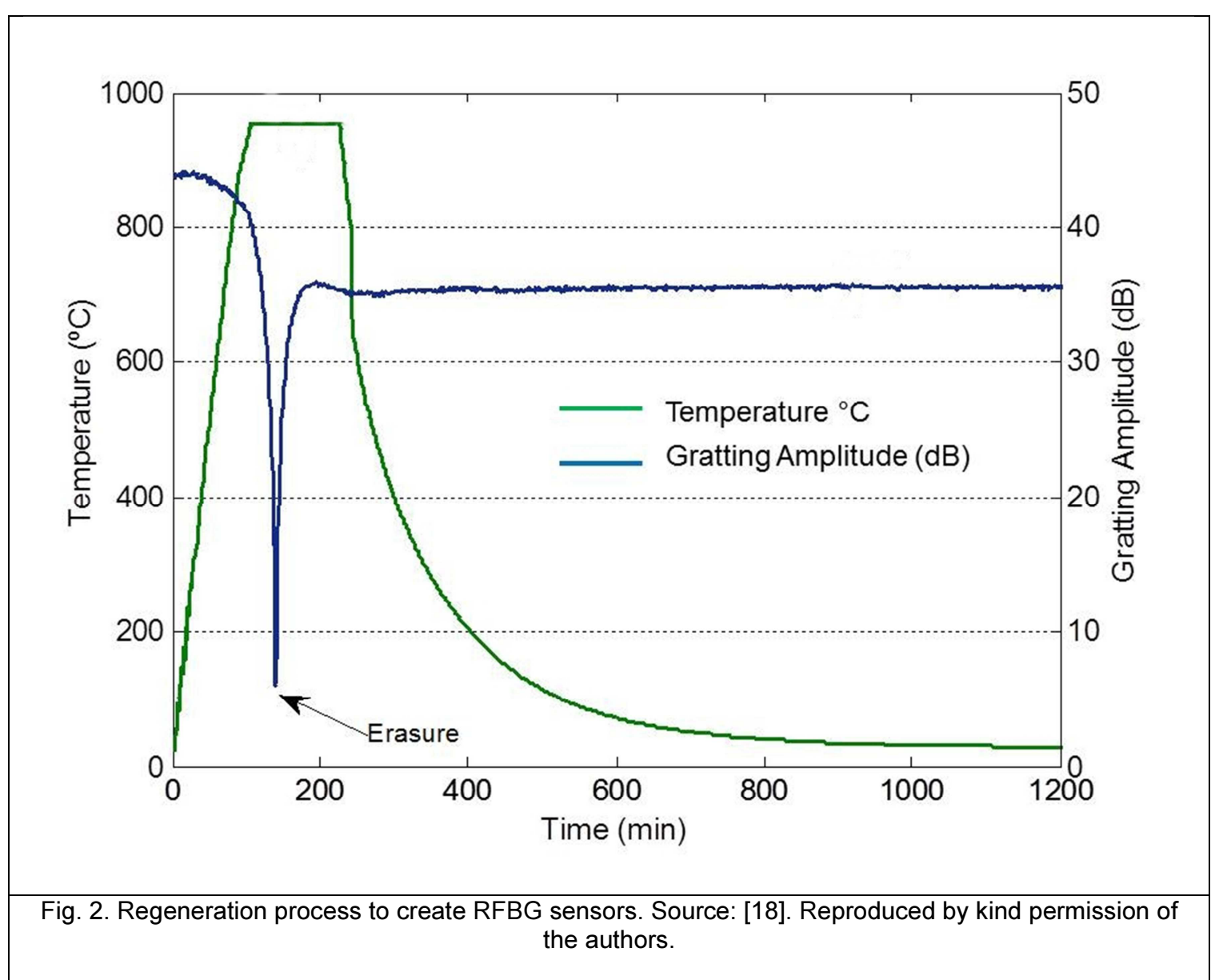

\subsection{RFBG sensor development and calibration.}

The sensors developed by the authors and tested in this work have a packaging composed of a single-bore metallic tube with a bore diameter of $2.5 \mathrm{~mm}$. The RFBG inside the tube is fixed in one of its ends and completely free to move in the other. By doing so, the tube holds the RFBG straight and also fulfills three important conditions:

1) It does not restrain any mechanical deformation of the RFBG, so that the shift in the Bragg wavelength is caused only by temperature variations.

2) It does not interfere with the sensing properties of the RFBG. This was checked by means of several tests described in [18].

3) It makes the sensor have a very short response time as detailed in [11].

The RFBG sensor was calibrated in a Carbolite MTF12/38/40 furnace that can reach maximum temperatures of $1250{ }^{\circ} \mathrm{C}$ (Fig. 3). The furnace guaranteed a uniform temperature distribution along its central portion, in which the optic sensor and a thermocouple were placed. Temperatures were increased in different steps from $10{ }^{\circ} \mathrm{C}$ to $1000^{\circ} \mathrm{C}$. In each temperature step, the temperatures measured by the thermocouple and the Bragg wavelengths measured by the optic sensor were recorded. All the data were recorded with a laptop and a MicronOptics sm125-500 fiber optic interrogator. This interrogator provided light for the fiber optic sensors, received the reflected light from the sensor and decoded and transferred information to the data acquisition system (computer). 
Torres-Gorriz B., Paya-Zaforteza, I., Calderon Garcia, P.A., Sales Maicas, S.

New fiber optic sensor for monitoring temperatures in concrete structures during fires

(2017) Sensors and Actuators, A: Physical, 254, pp. 116-125. DOI: 10.1016/j.sna.2016.12.013

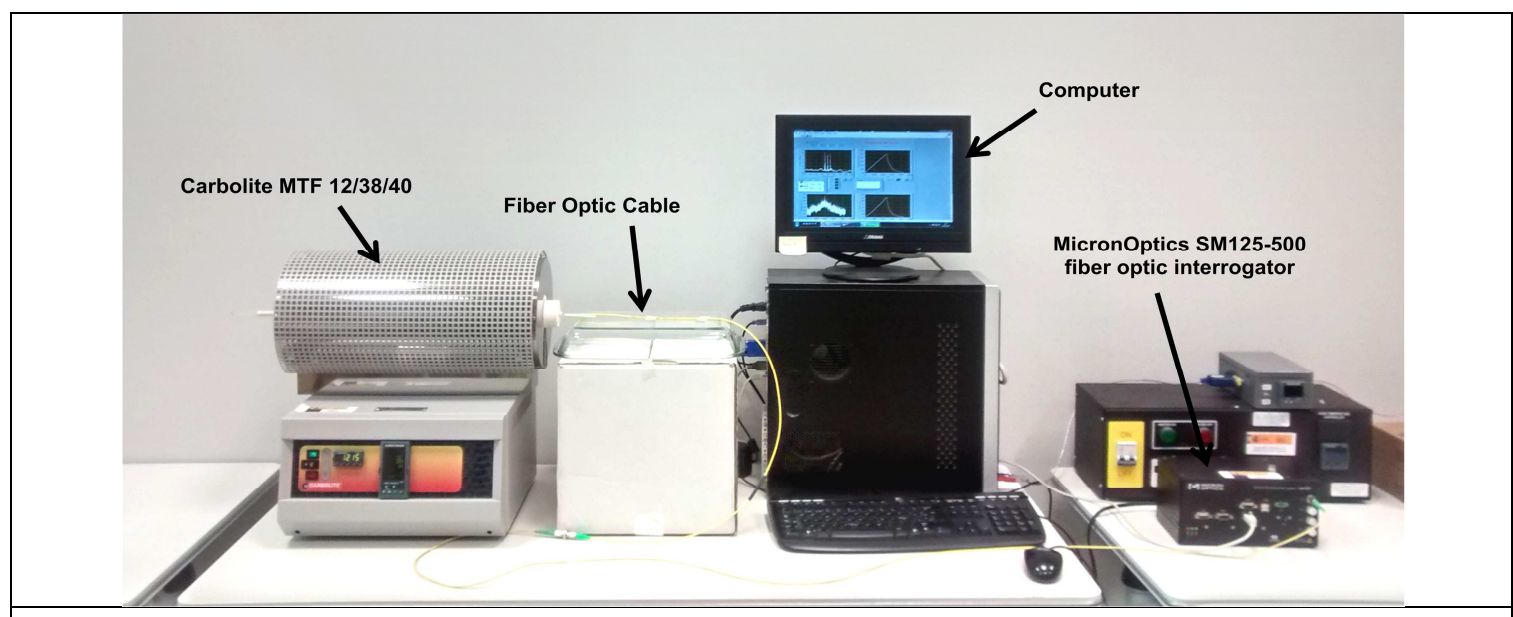

Fig. 3. Carbolite MTF12/38/40 furnace and MicronOptics sm125-500 fiber optic interrogator used in RFBG sensor development and calibration.

The recorded data were plotted on a graph (see Fig. 4) and the Least Squares Method was used to find the mathematical relationship that expresses the temperatures as a function of the Bragg wavelength shifts (see Eq. (5)). The expression of Eq. (5) has a correlation coefficient of $R^{2}=0.996$, which indicates an almost perfect fit.

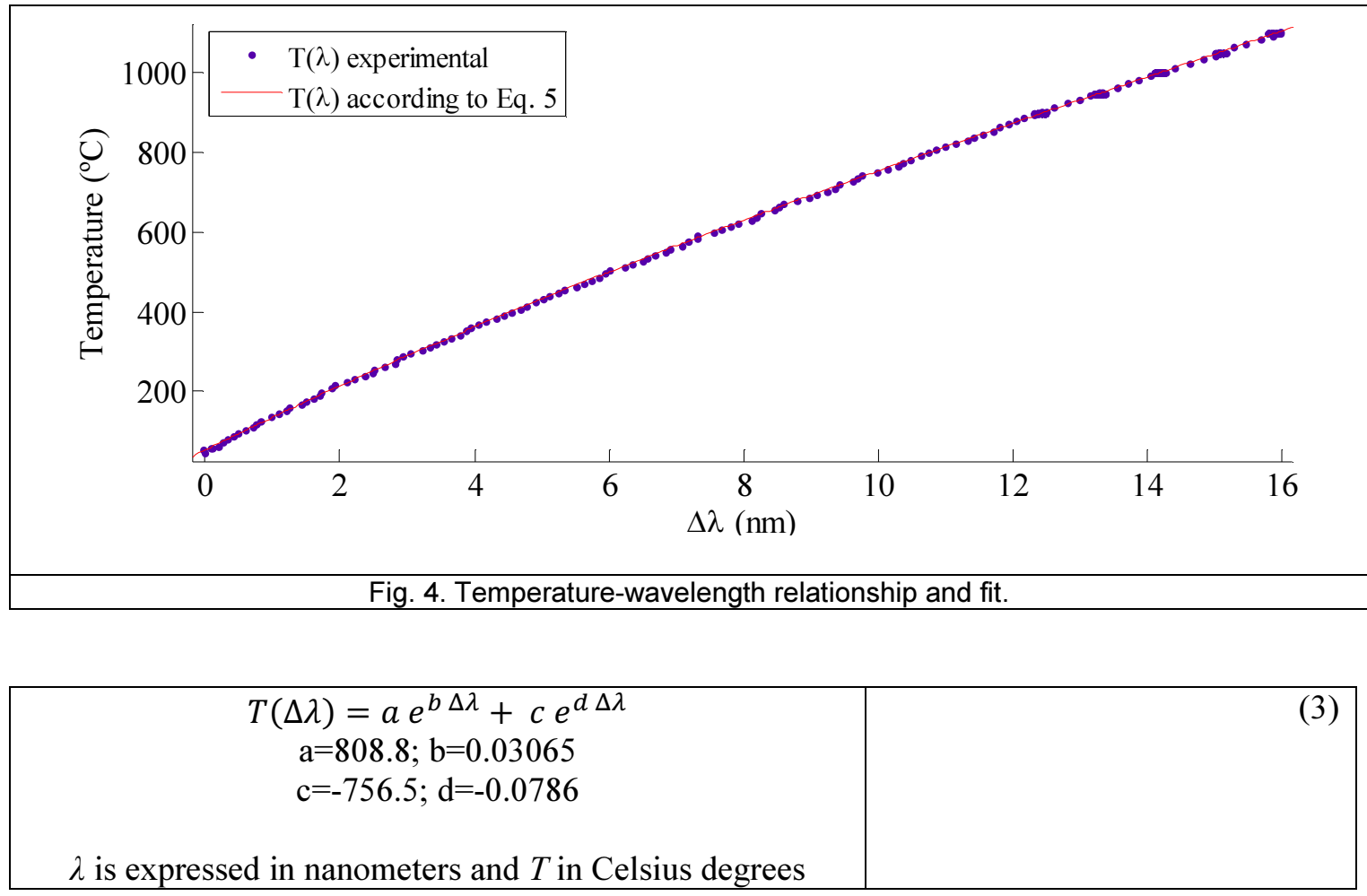

It is important to highlight that the coefficients $a, b, c$ and $d$ depend on the initial wavelength $\lambda_{0}$ of the sensor, and the values of Eq. (3) are for a $\lambda_{0}$ value equal to $1557.255 \mathrm{~nm}$. The tests were repeated several times to check the repeatability of the thermal response at high temperatures. 


\section{Fire test.}

\subsection{Experimental test}

The fiber optic sensors were installed embedded in a reinforced concrete beam spanning $5.8 \mathrm{~m}$ and built with concrete with a compressive strength of $35 \mathrm{MPa}$ and steel with a yield strength of $500 \mathrm{MPa}$. Fig. 5 shows the dimensions and construction details of the beam. The beam was designed to sustain the loads of a typical residential building and the minimum cover of the steel reinforcement was $5 \mathrm{~cm}$. The concrete beam was tested at 90 days.

\section{Elevation}

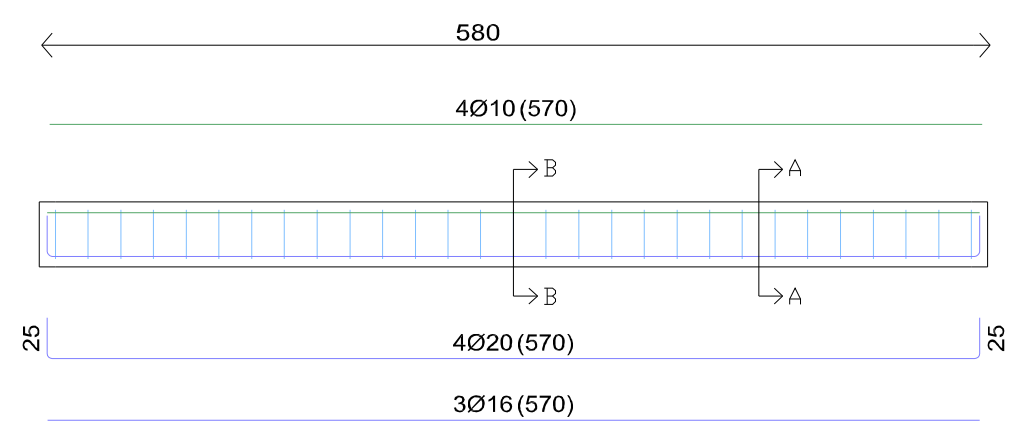

Cross section AA.

Fig. 5. Construction details of the beam. All the geometric dimensions are given in $\mathrm{cm}$. The diameter of all the bars is expressed in $\mathrm{mm}$. FO sensors were located in the Section B-B.

The mid-span section (Section B-B in Fig. 5) of the beam was monitored with 9 fiber optic sensors designed by the authors and 9 Type $\mathrm{K}$ thermocouples, numbered and positioned as shown in Figure 6. Sensors FOS1, FOS8 and FOS9 were installed under the beam's longitudinal reinforcement in order to 1) protect the sensors and wiring when the concrete was being poured and vibrated, and 2) use the reinforcement to anchor the sensors. FOS2 to FOS7 required an additional steel structure of $6 \mathrm{~mm}$ diameter bars, since there was no longitudinal reinforcement to fix the sensors to. This structure was fixed to the longitudinal and transverse reinforcement of the beam with wire. 


\section{Cross section}

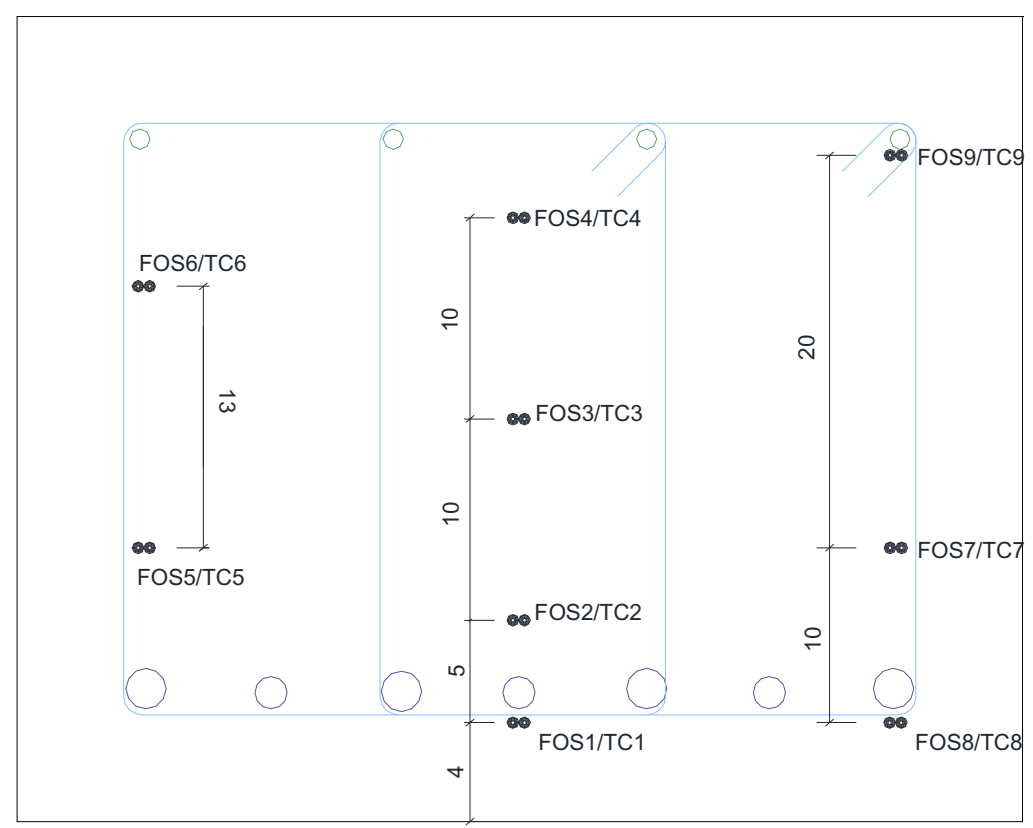

Fig. 6. Monitoring of the reinforced concrete beam. Location of the Fiber Optic Sensors (FOS) and Thermocouples (TC) in the beam cross section. All the geometric dimensions are given in $\mathrm{cm}$.

The sensors were fixed to the reinforcing bars with wire (Fig.7a) to keep them from being dislodged during pouring. After the concrete had set the sensors were checked for possible damage and correct operation.

For protection when the concrete was being poured and to allow the cables to conform to the angles between the longitudinal and transverse bars, they were placed under the reinforcement inside a flexible PVC tube to avoid being damaged by aggregate during the pouring. This tube would no longer be needed after hardening and as it could not resist temperatures over $120^{\circ} \mathrm{C}$ it was expected to disintegrate during the tests. This was not the case of the fiber optic cable connecting the sensors since it had a silica glass core able to withstand the maximum temperatures expected in the tests. It is important to note that as each encapsulated RFBG was $1 \mathrm{~cm}$ long, the temperature value given by each sensor was the mean value recorded along this length.

Type-k thermocouples with ceramic insulation were used to verify the behavior of the fiber optic sensors. These thermocouples were installed as close as possible to the fiber optic sensors as shown in Figs. 6 and 7. 


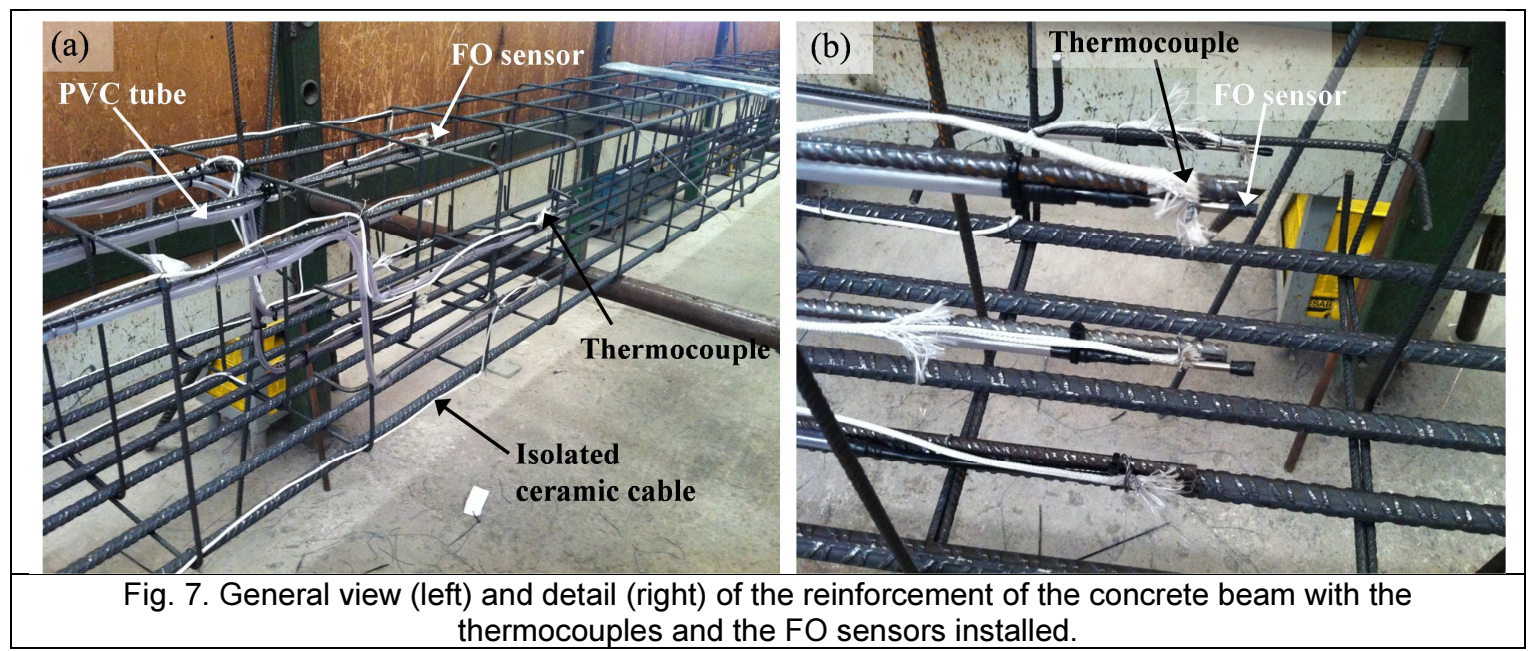

The concrete beam monitored with fiber optic sensors was subjected to a fire test in which the ISO-834 standard fire curve and two point loads were applied. The fire test had a duration of 77 minutes, although the sensors collected data for 130 minutes. We believe this to be the first time fiber optic sensors embedded in concrete have been subjected to such rigorous testing.

A $5 \times 3.8 \times 2 m$ rectangular furnace was used for the test, with eight gas burners along parallel sides of the chamber. Fig. $8 a$ shows the concrete beam in the furnace previous to the fire test. The beam was simply supported and placed in the upper part of the furnace, where the temperature is more uniform. Furnace temperature was controlled by eight plate thermometers (PT) in the chamber close to the concrete beam. The PTs were installed with their insulated face towards the specimen, so that their exposed face received the same radiant heat flux as the beam and the PTs were not affected by radiation from the specimen. The plate thermometers received a radiant heat flux similar to the beam under test [4] and in these conditions the adiabatic temperature measured by them can be used to analyze heat transfer phenomena in structural elements submitted to fires.

A load of $125 \mathrm{kN}$ was applied with a single hydraulic jack. The total load was split into two loads of $62.5 \mathrm{kN}$ at one-third of the total length by means of a rigid steel beam, in order to have a constant bending moment acting on the central third of the beam. The test setup, the hydraulic jack and the rigid steel beam can be seen in Figure $8 \mathrm{~b}$. 

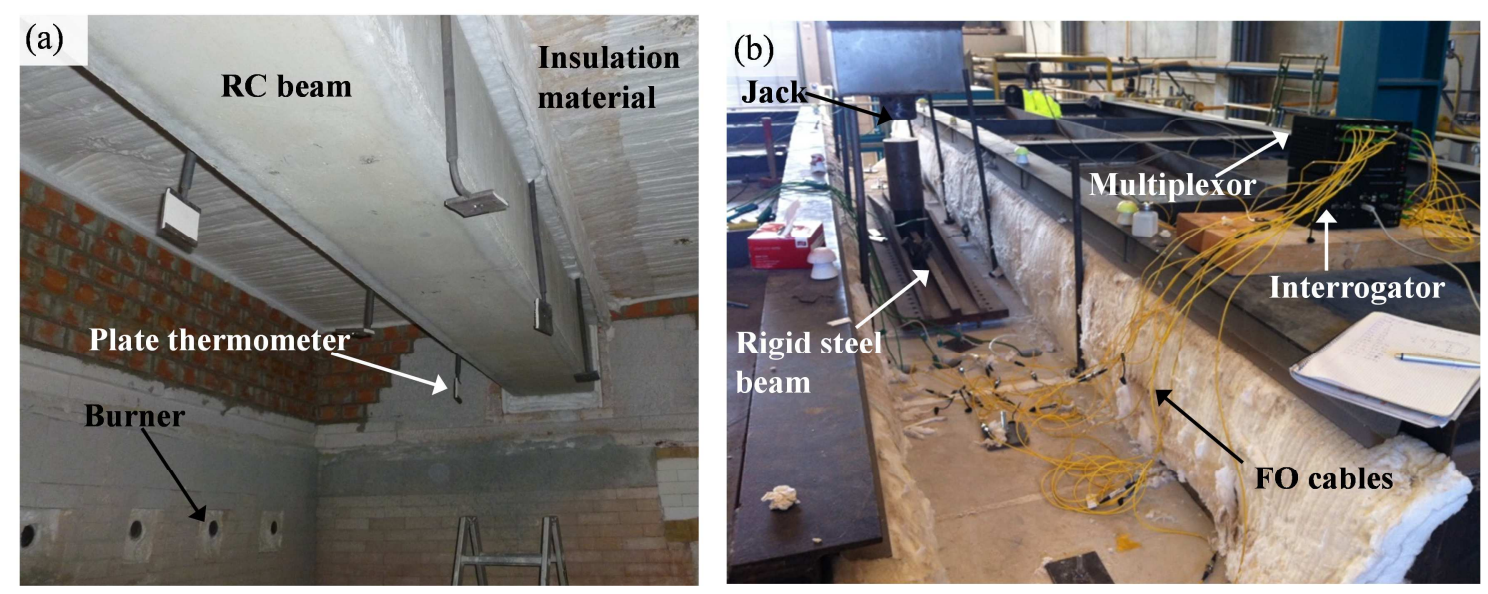

Fig. 8. Set-up of the fire test. (a) General view of the RC beam in the furnace before the test. (b) Hydraulic jack, interrogator, multiplexor and fiber optic cables.

In addition to the sensors, the temperature monitoring system had three other components: a reading unit, a cable network and a data management system. The reading unit was a Micron Optics sm125-500, with a wavelength range of 1510-1590 $\mathrm{nm}$, four optical channels and a frequency of $1 \mathrm{~Hz}$. As 9 channels were needed (one for each sensor), a multiplexer Micron Optics sm041-416 was used to extend the number of channels from the interrogator. Micron Optics Enlight sensing analysis software [26] was used for data acquisition, definition, and visualization. Reflected spectrum responses and Bragg wavelengths were recorded every second.

\subsection{Numerical model.}

A 2D nonlinear heat transfer model of the RC beam's cross section was developed on Lusas software [27] to obtain the theoretical temperatures inside the beam.

The heat transfer model uses flat thermal field QFD8 finite elements, which are square 2D FEs with 4 nodes and one degree of freedom per node, corresponding to temperature. As each QFD8 element is $0.5 \mathrm{~cm}$ long, the model had a total of 8,000 FEs and 64,000 nodes.

Concrete thermal properties were defined according to Eurocode 2, Part 2 [28] considering that calcareous aggregates were used. Thermal loads were applied to the exposed faces of the beam using the temperatures measured by the PTs during the test. To do so, an initial temperature equal to $13^{\circ} \mathrm{C}$ was assigned to the cross section of the beam according to the measurements taken on site. The convective heat transfer coefficient was defined as $25 \mathrm{~W} /\left(\mathrm{m}^{2} \mathrm{~K}\right)$, the emissivity of the exposed surfaces was defined as 0.8 and fire emissivity was 1 . The specific heat coefficient was taken as $1000 \mathrm{~J} /(\mathrm{kg} \mathrm{K})$ and the thermal conductivity as an average value equal to $1.3 \mathrm{~W} / \mathrm{m}^{\circ} \mathrm{K}$ (considering calcareous aggregates). 


\section{Results and discussion.}

Figure 9 shows the ISO834 theoretical temperature curve and the furnace temperature curve obtained as the mean of those measured by the 8 PTs. An excellent fit can be seen between both curves, thanks to the pressure stabilizing at around $16 \mathrm{~Pa}$ for almost the entire test. Figure 10a shows a photo of the RC beam after the test and 10b gives the cross section temperatures provided by the heat transfer finite element model of the experiment at the end of the fire test (minute 130).
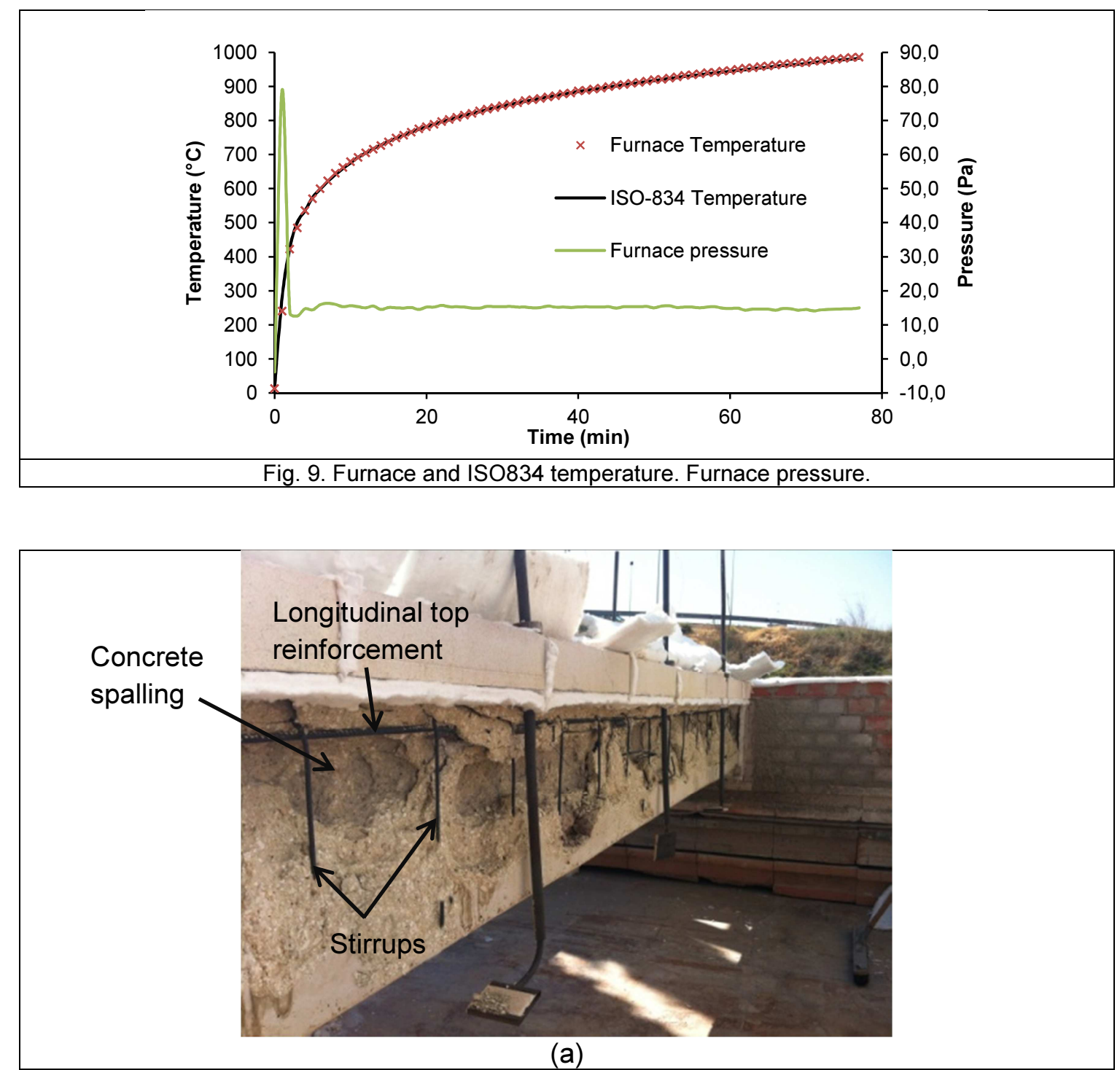


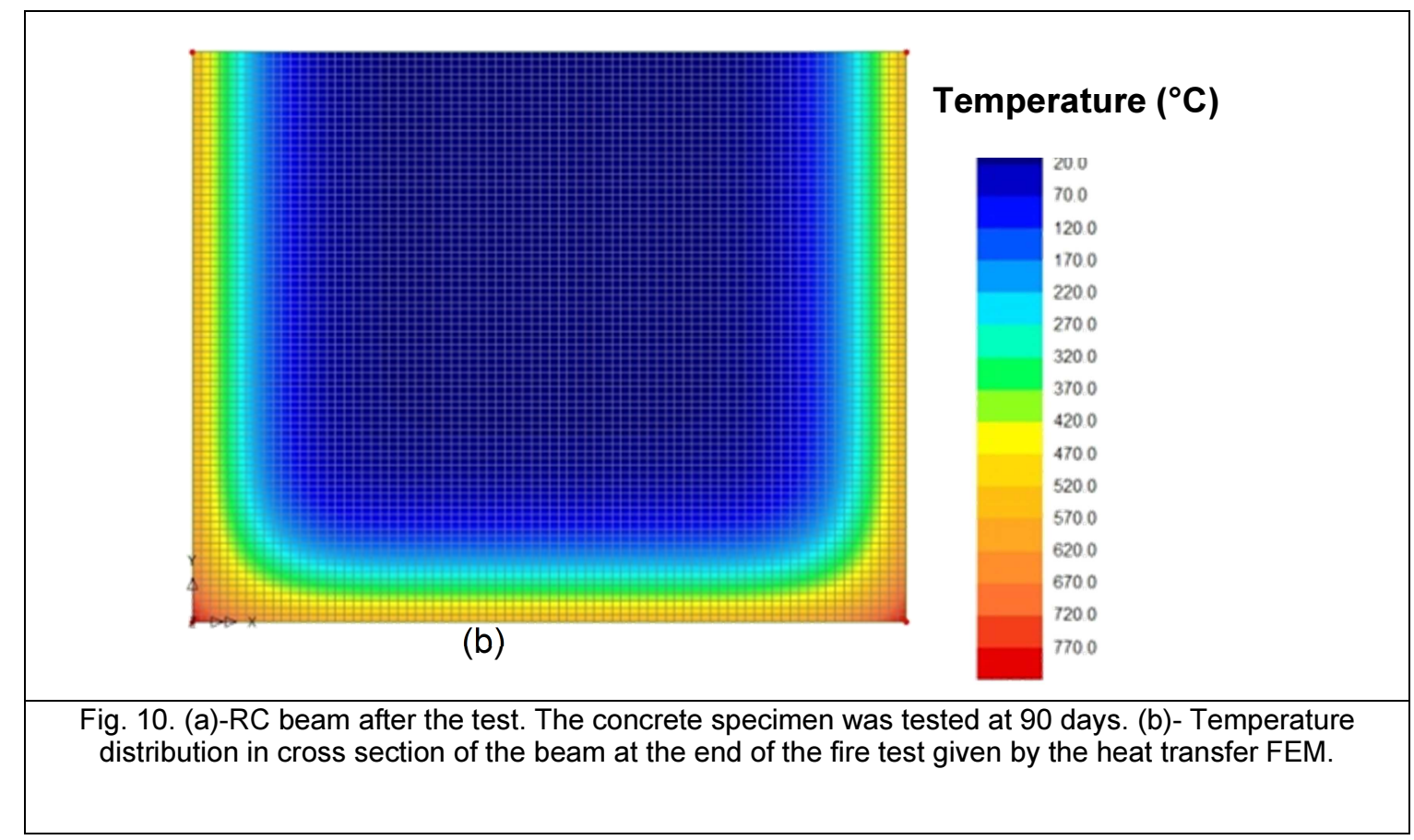

Figure 11 gives the temperatures recorded by the optic sensors and thermocouples installed on the axis of symmetry of the studied cross section (FOS1 to FOS4 and TC1 to TC4) also the theoretical temperatures obtained at these points by the FE model's numerical elements (FEM1 to FEM4).

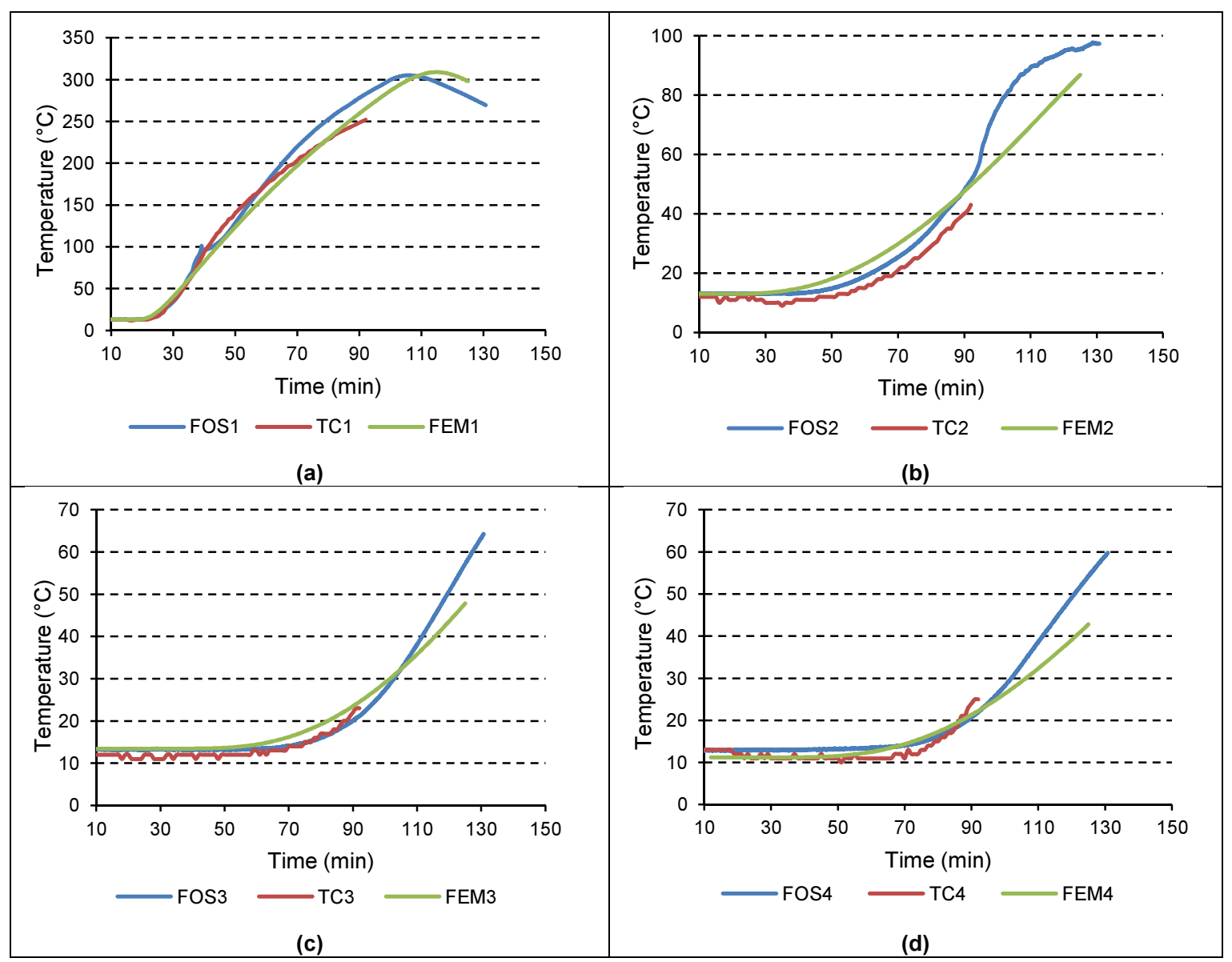


Fig. 11. Temperature evolution at Points $1,2,3$ and 4 on the cross section's axis of symmetry.

From these results it can be seen that:

- As expected, the highest temperatures were found in the zone near the underside of the beam, which was directly exposed to the fire, e.g. the maximum temperatures recorded by FOS1, FOS2, FOS3 and FOS4 were $308.8,97.4,64.3$ and $59.8^{\circ} \mathrm{C}$, respectively.

- The graphs show that the temperatures measured by both thermocouples and optic sensors were quite similar and followed the same pattern. The recorded temperatures are also close to those predicted by the theoretical FE model. For example, Table 1 compares the temperatures at $92 \mathrm{~min}$ in optic sensors, thermocouples and theoretical model. The largest differences between the temperatures recorded by the optic sensors and FE model are seen to be less than $8.2^{\circ} \mathrm{C}$ ( $3 \%$ of the temperature recorded). The maximum difference between the thermocouple and theoretical temperatures at Point 1 is $18.6^{\circ} \mathrm{C}$, which represents $6.8 \%$ of the temperature measured. However, at Point 2 the difference is $9.1{ }^{\circ} \mathrm{C}$ or $17.4 \%$ of the measured temperature. In both cases the differences are insignificant as regards the safety of the structure and could be attributed to the slight variations in the final position of the sensors in relation to their theoretical position. The greatest differences, between FOS1 and TC1, were as expected, as they were closest to the beam surface and the spalling of the concrete left them exposed, which meant that the differences with the theoretical temperatures were higher. Sensors FOS 2 to FOS 4 and TC2 to TC4 were furthest from the sides of the beam exposed to the fire, so that the spalling phenomenon had slight influence on their measurements.

\begin{tabular}{ccccccc} 
Point & FOS $\left({ }^{\circ} \mathbf{C}\right)$ & TC $\left({ }^{\circ} \mathrm{C}\right)$ & FE $\left({ }^{\circ} \mathrm{C}\right)$ & $\begin{array}{c}\text { \% Difference } \\
\text { (FOS-TC)/TC }\end{array}$ & $\begin{array}{c}\text { \% Difference } \\
\text { (FOS-FE)/FE }\end{array}$ & $\begin{array}{c}\text { \% Difference } \\
\text { (TC-FE)/FE }\end{array}$ \\
\hline $\mathbf{1}$ & 278.9 & 252.1 & 270.7 & 10.6 & 3 & 6.8 \\
$\mathbf{2}$ & 48.6 & 43 & 52.1 & 13 & 6.7 & 17.4 \\
$\mathbf{3}$ & 20.7 & 21.7 & 22.3 & 4.6 & 7.1 & 2.7 \\
$\mathbf{4}$ & 22.6 & 24.1 & 22.5 & 6.2 & 0.4 & 7.1 \\
\hline
\end{tabular}

Table 1. Temperatures in optic sensors, thermocouples and theoretical model.

Figure 12 shows the temperatures recorded by the optic and electrical sensors near the vertical sides of the beam exposed to the fire at Points 5,6 and 7 in Figure 6 (FOS5, FOS6, FOS7, TC5, TC6, TC7), also the theoretical temperatures obtained from the FE model (FEM5, FEM6, FEM7). Figure 13 shows the state of the beam and Sensors FOS5 and TC5 after the test. In view of these results, the following comments can be made:

- The behavior of the sensors 5, 6 and 7 is not as satisfactory as those at Points 1 to 4 . After $90 \mathrm{~min}$, none of the sensors provided data and some of the results were erratic, such as the peaks registered by the thermocouples. This behavior was due to sensors 5,6 and 7 being on the sides directly exposed to the fire, where, as can be seen in Figures 10 and 13, a lot of damage was caused by concrete spalling. 
- Until approximately $41 \mathrm{~min}$, FOS5 and TC5 behaved similarly to each other and showed a good fit with the results obtained from FEM5 (Figs. 12a and 12b), except for a sharp and sudden change measured by TC5 around $26 \mathrm{~m}$. Small discrepancies observed between the values given by optic sensors, thermocouples and the FE model, with a maximum value of $14 \%$ of the measured temperature, can be attributed to small differences between the real position of FOS5 and TC5 with respect to the fire and the position of the sensors assumed in the FEM.

- Optic sensor FOS5 stopped providing data about 41 min (Figs.12a and 12b) due to concrete spalling after measuring a temperature of $189.3^{\circ} \mathrm{C}$. The breakage probably did not occur in the sensor itself as its packaging had sufficient mechanical resistance, but in the cable joining it to the data collection system, which was embedded inside the beam. This hypothesis is supported by the final state of the beam and sensors after the test in the area around FOS5, as can be seen from the photo in Figure 13a.

- The jump in temperature registered by TC5 around 26 min, shown in Figure $12 \mathrm{~b}$, can be attributed to a failure in the electric sensor, probably due to a bad contact between its two poles. After $51 \mathrm{~min}$, the data provided by TC5 show anomalous behavior, probably due to spalling leaving it exposed to the action of the fire (Fig.12a). Around $65 \mathrm{~min}$, TC5 showed a temperature of approximately $852^{\circ} \mathrm{C}$, after which there are sharp and sudden temperature variations, which indicate that the sensor was not operating properly. Figure 13b shows the state of this sensor after the test, which supports the view that it could not have been working correctly.

- Sensors 5 and 7 did not provide identical temperature measurements in spite of being in symmetrical positions, due to the different influence of spalling effects.

- The temperatures registered at Position 6 were similar to those from Position 5 and the FE model up to $30 \mathrm{~min}$ (Figs.12c and 12d). Sensor FOS6 stopped operating at $46 \mathrm{~min}$ when it had recorded a temperature of $136^{\circ} \mathrm{C}$ and TC6 stopped at $60 \mathrm{~min}$ after recording $164^{\circ} \mathrm{C}$, both stopped because of spalling damage.

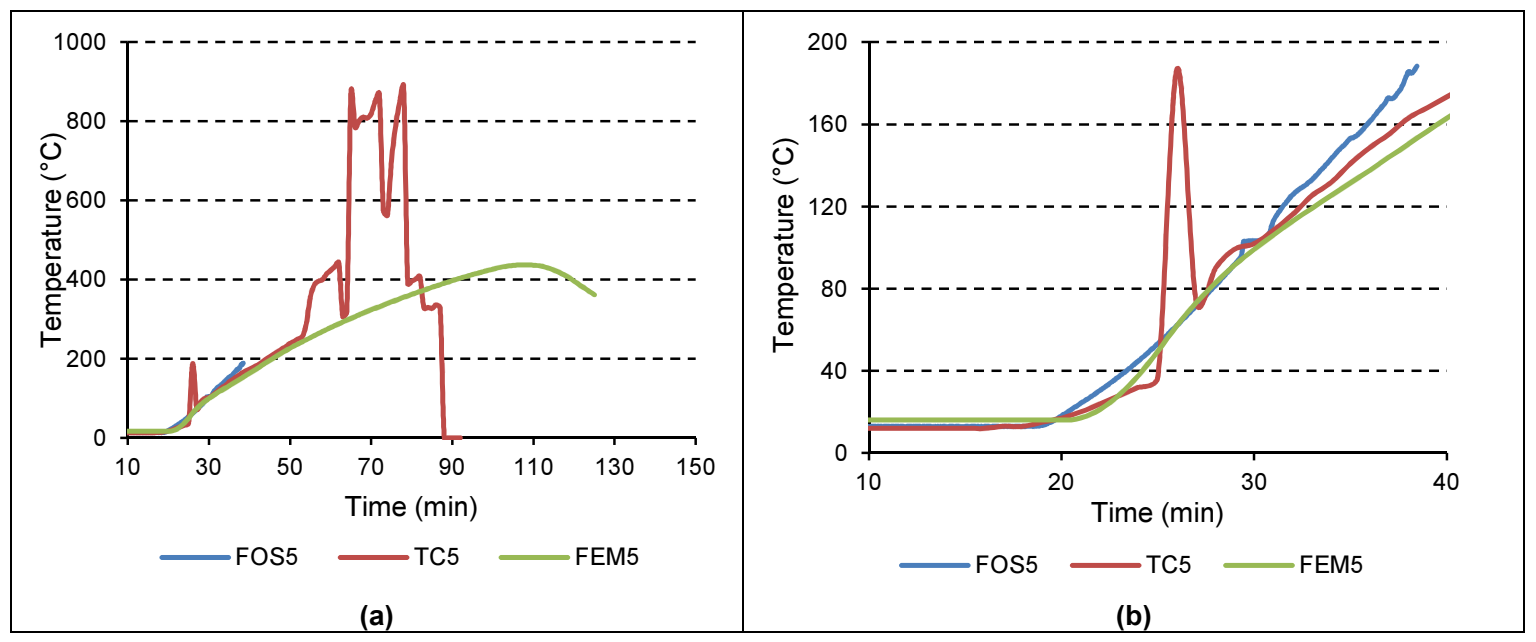


Torres-Gorriz B., Paya-Zaforteza, I., Calderon Garcia, P.A., Sales Maicas, S.

New fiber optic sensor for monitoring temperatures in concrete structures during fires

(2017) Sensors and Actuators, A: Physical, 254, pp. 116-125. DOI: 10.1016/j.sna.2016.12.013
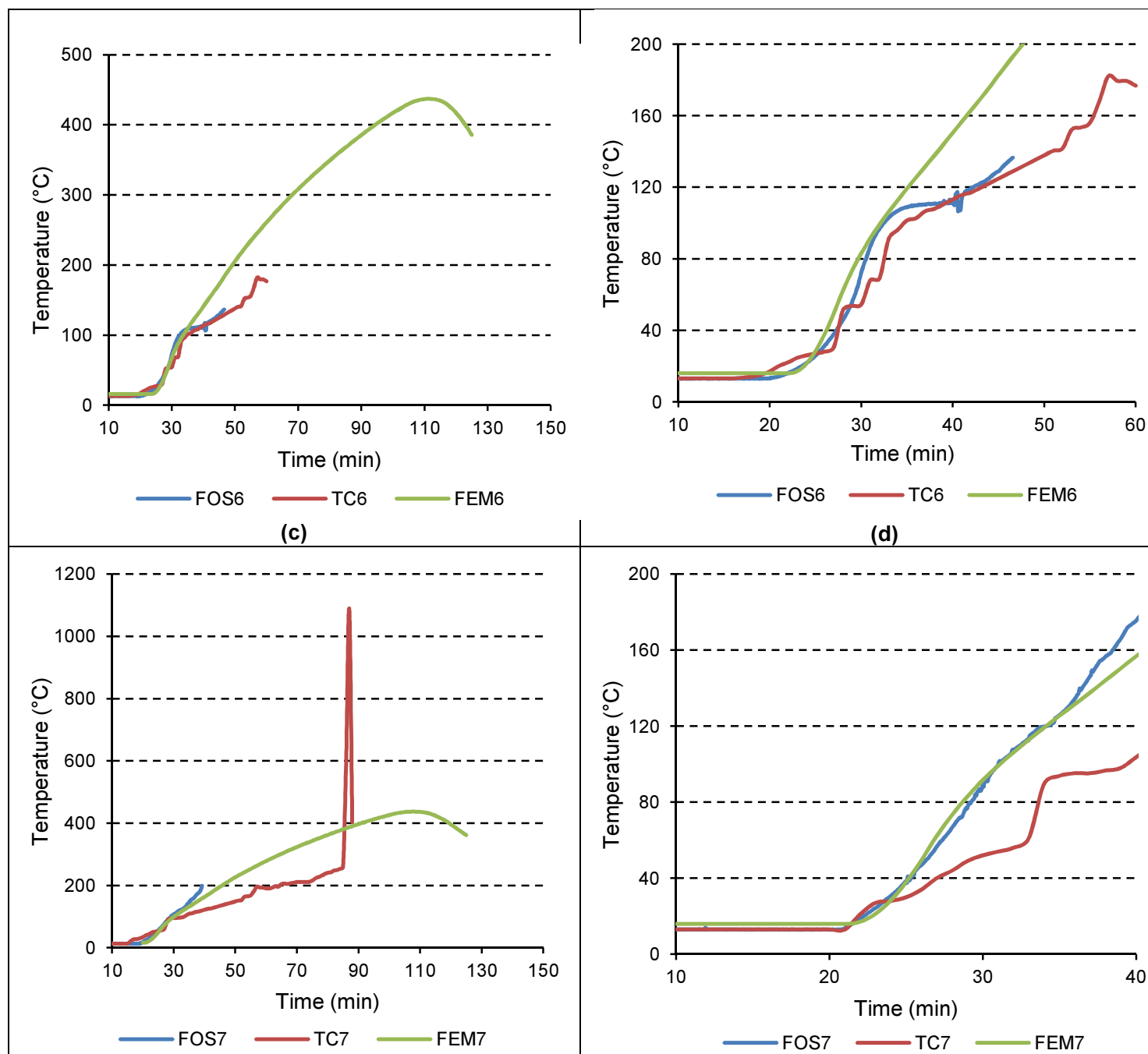

(e)

(d)

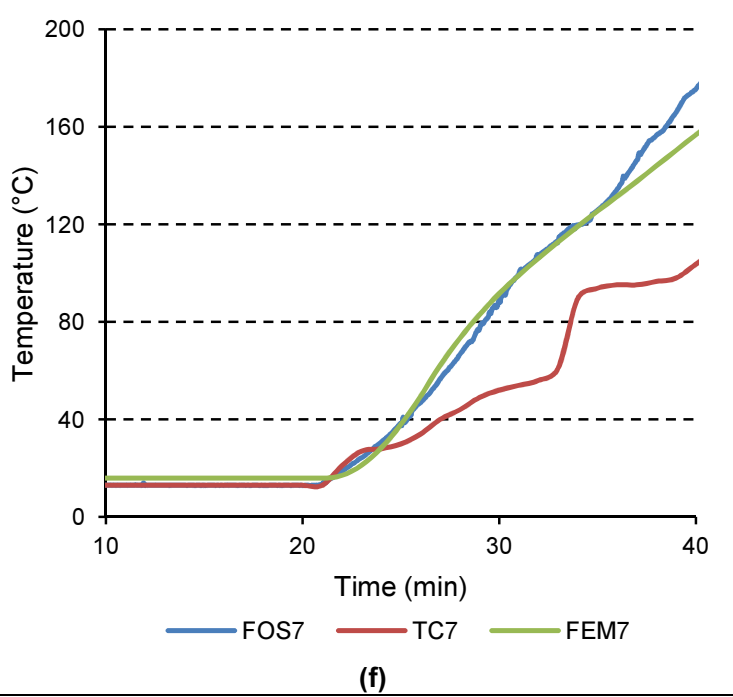

Fig. 12. Temperature evolution at Points 5, 6 and 7. Note that Figs. $12 \mathrm{a}, 12 \mathrm{c}$, and $12 \mathrm{e}$ show full test (130 min) whereas Figs. $12 b, 12 d$ and $12 f$ show only a part of the test.
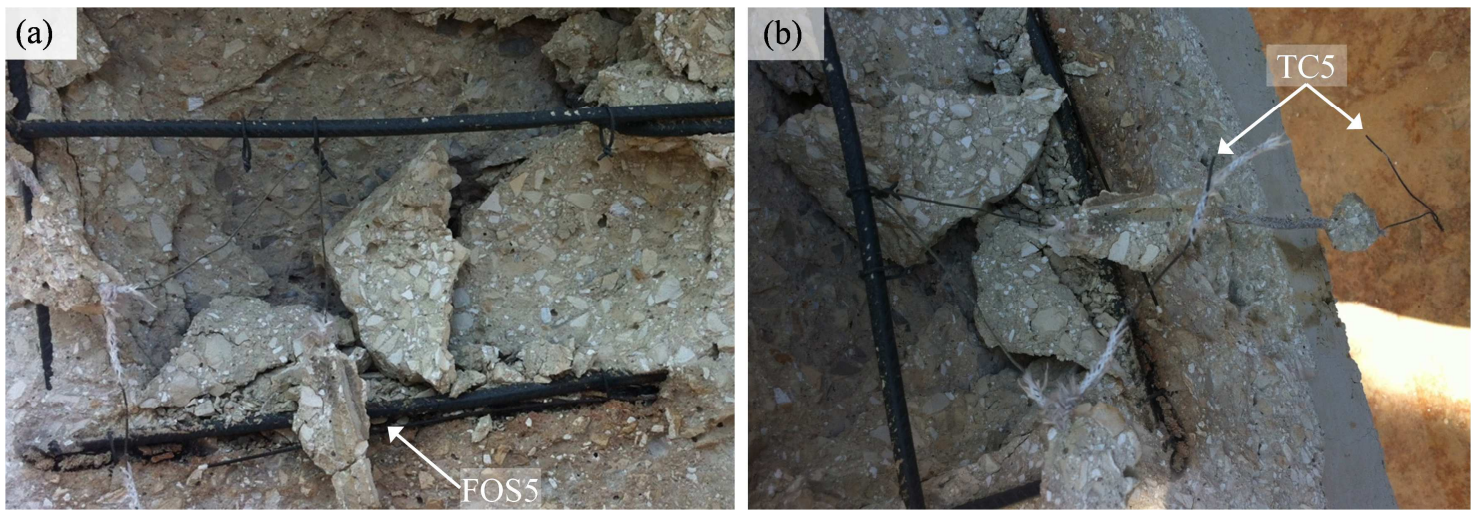

Fig. 13. Sensors FOS5 (left) and TC5 (right) at the end of the fire test. 
Torres-Gorriz B., Paya-Zaforteza, I., Calderon Garcia, P.A., Sales Maicas, S.

New fiber optic sensor for monitoring temperatures in concrete structures during fires

(2017) Sensors and Actuators, A: Physical, 254, pp. 116-125. DOI: 10.1016/j.sna.2016.12.013

Finally, Figures $14 a$ and $14 b$ show the temperatures from the optic and electrical sensors at Points 8 and 9 (upper and lower corners of the cross section close to a vertical face exposed to the fire) and the theoretical temperatures provided by the FE model.

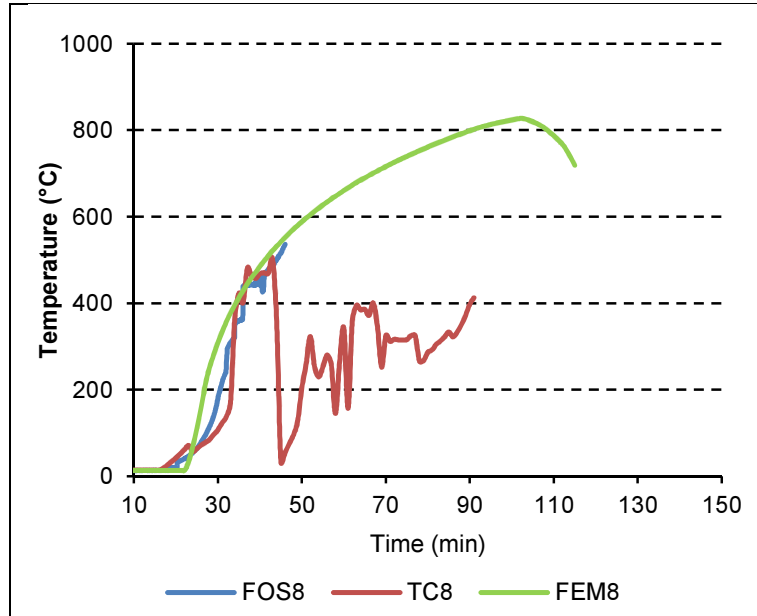

(a)

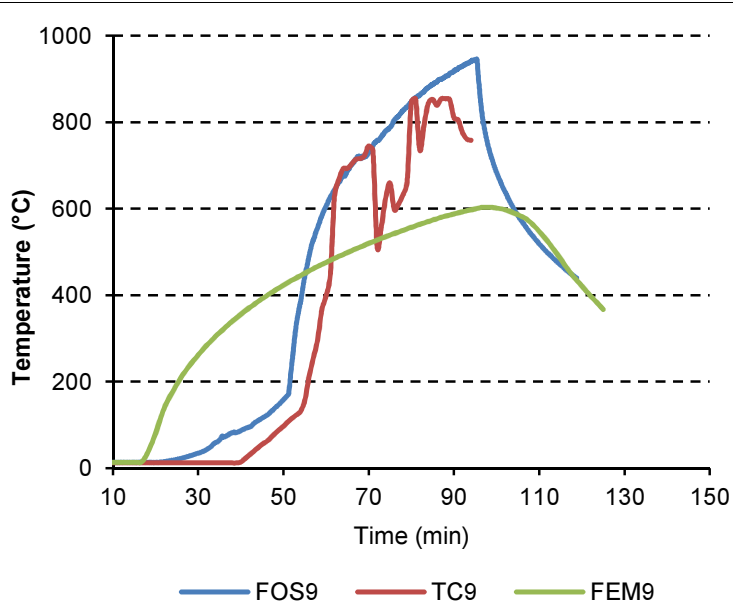

(b)

Fig. 14. Temperature evolution at Points 8 and 9.

From these results it can be seen that:

- In general, the temperatures measured at these two points show larger differences than those observed at other points. This is because both Point 8 and Point 9 were in more problematic positions due to being placed at the corners. Point 8 was highly exposed to the fire and thus prone to suffer spalling, while 9 was very close to the furnace's protective insulation, which affected its measurements.

- FOS8 and TC8 registered the temperatures correctly up to approximately $45 \mathrm{~m}$, when the temperatures measured were around $550^{\circ} \mathrm{C}$. FOS 8 stopped operating at that time and TC 8 began to give erratic readings, both problems were probably due to the intense spalling at the corners of the cross section (Fig.15).

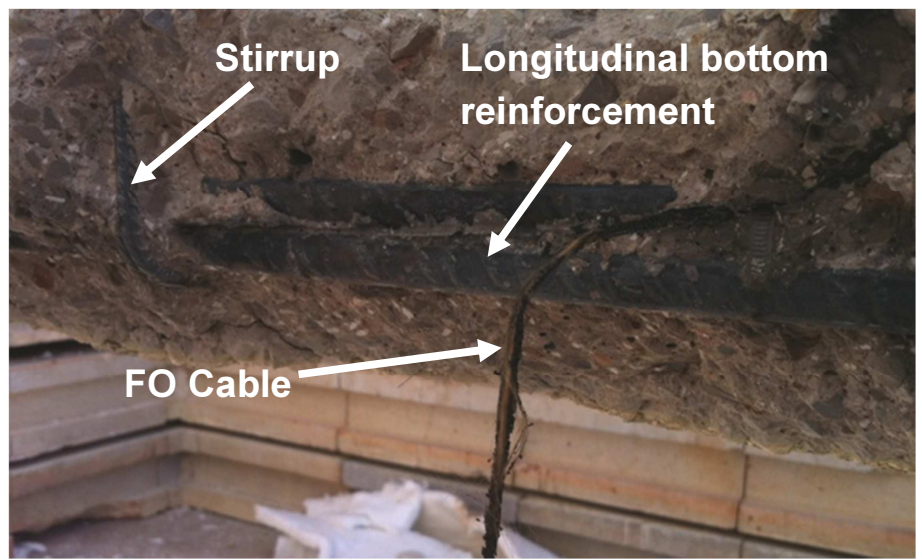

Fig. 15. Spalling in the lower corner of the monitorized cross section. The fiber optic cable can be seen to 
be severely damaged. The thermocouple has disappeared.

- $\quad$ The most widely dispersed results were given by FOS9 and TC9 (Fig.14b) and are analyzed below.

- The temperatures recorded by FOS9 show two clearly different zones. At the start, the temperature rose more slowly than at other points until reaching $165^{\circ} \mathrm{C}$ at $51 \mathrm{~min}$, because the sensor was placed in a zone affected by the furnace insulation and heat dissipaters, such as mineral wool. These elements influenced the transmission of heat to the interior of the beam but were not included in the FE model. After 51 min, there was an abrupt change in the temperature trend, which rose rapidly to $953^{\circ} \mathrm{C}$ due to spalling, which left the sensor completely exposed to the fire but did not stop it operating, as can be seen in Figure 16. The sensor thus finally recorded a temperature close to that in the furnace, which was $963^{\circ} \mathrm{C}$ at that time.

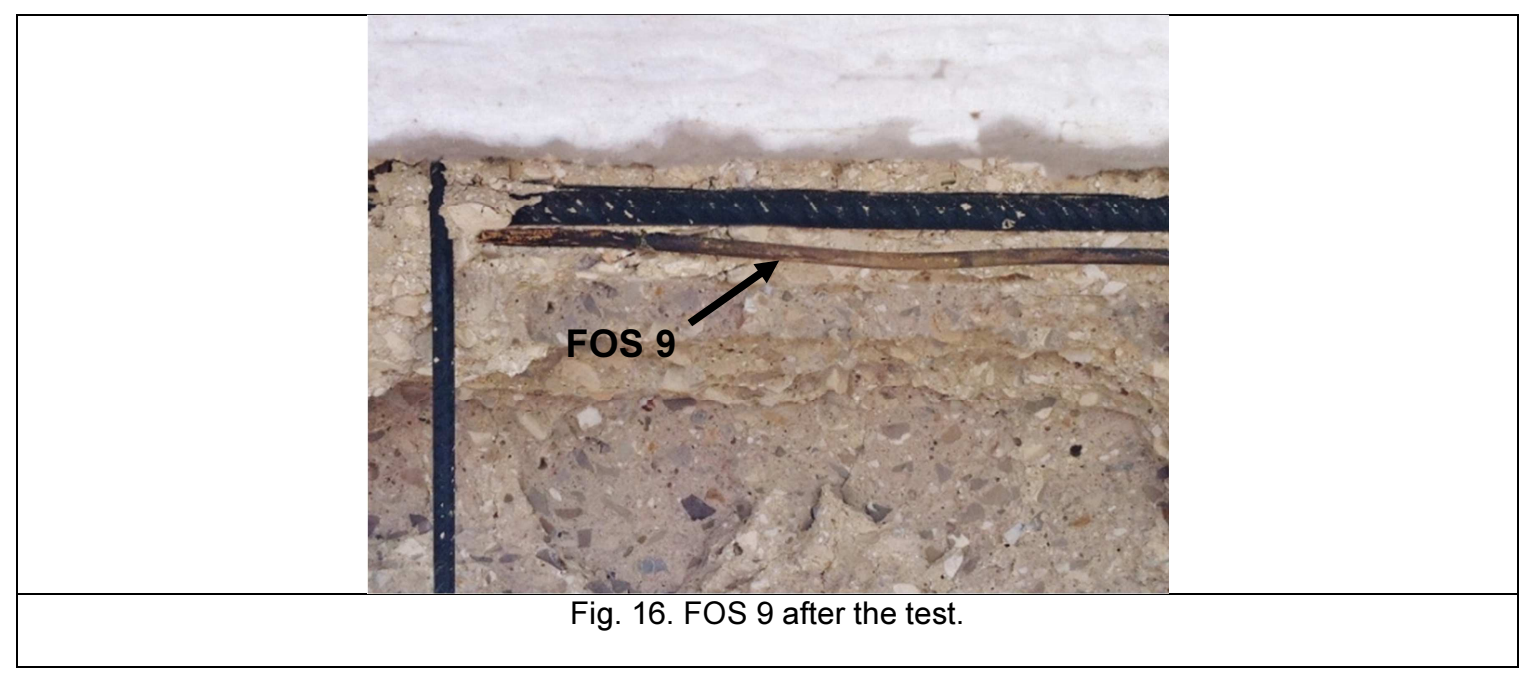

- TC9 followed a similar trend to FOS9, although after $72 \mathrm{~min}$ it began to give erratic readings with large temperature fluctuations, which could have been due to bad contact due to its cables being damaged.

- Differences were observed in the readings given by the FOS and the thermocouples, although both followed the same general pattern. These temperature differences could have been due to a number of reasons, such as small vertical or horizontal variations in the positions of the sensors, or erratic operation or breakage due to spalling. It should be remembered that the sensors were very close to the beam surfaces exposed to the fire with a high temperature gradient (Fig.10b), so that small variations in the position of the sensors had a considerable effect on the value of the temperatures measured.

\section{Conclusions and future work.}


This paper proposes a new optic sensor based on regenerated Bragg gratings designed to measure high temperatures in concrete structures. The sensor was subjected to a standard fire test in an RC beam subjected to loads similar to those normally found in building structures. The optic sensors were installed in the mid-span cross section of the beam, which was subjected directly to flames and high temperature gradients (of the order of $200^{\circ} \mathrm{C} / \mathrm{min}$ ) as would be the case in a real fire. The optic sensors registered temperatures of up to $953^{\circ} \mathrm{C}$, which were compared to those obtained from thermocouples and the results from an FE model of the test. The principal conclusions that can be drawn from this test are as follows:

- To operate correctly, the monitoring system must be carefully installed and adequately protected. It is recommended to place the sensors and wiring below the reinforcement in the structure to protect them from damage during concrete pouring and vibration.

- The sensors recorded very similar temperatures to those obtained from the thermocouples and in general their measurements followed the trends predicted by the FE model. The discrepancies between the temperatures measured by the sensors and the FE model were due to the influence of concrete spalling and the presence of insulation elements that were not included in the FE model. It can therefore be said that the optic sensors operated correctly.

- The proposed packaging of the fiber optic sensors behaved well and was able to withstand the harsh conditions imposed by the fire. However, the wiring that connects the sensors to the reading unit needs special attention, as concrete spalling damaged it in several places, with the result that some of the sensors stopped operating before the end of the test. Further research is therefore necessary to determine the correct design of the wiring and how it should be connected to the sensors to avoid being damaged by spalling. Future research should also complete the work initiated by Rinaudo et al. [5] on defining monitoring strategies for structures submitted to fire loads.

\section{Acknowledgments.}

This work was made possible by the support from the Universitat Politècnica de València, the Spanish Ministry for Science and Innovation (Research Project BIA201127104 and TEC2011-29120-C05-05) and the Spanish Ministry of Public Works (Project Sopromac P41/08). 


\section{References:}

[1] Sun-Jong Park, Hong Jae Yim, Hyo-Gyoung Kwak. Effects of post-fire curing conditions on the restoration of material properties of fire-damaged concrete. Construction and Building Materials 99 (2015) 90-98.

[2] G. Peris-Sayol, I. Paya-Zaforteza, S. Balasch-Parisi, J. Alos-Moya, Detailedanalysis of the causes of bridge fires and their associated damage levels, ASCEJ. Perform. Constr. Facilities (2016), http://dx.doi.org/10.1061/(ASCE)CF.1943-5509.0000977.

[3] S. Domínguez Martín, C. Simal Pierna, E.L. García Díez. Fires during 2005 in Spain: A forest fire in Guadalajara and an urban fire in Windsor building (Madrid). Forest Ecology and Management 234S (2006) S72.

[4] Rinaudo P., Torres B., Paya-Zaforteza I., Calderón P.A., Sales S. Evaluation of new regenerated fiber Bragg grating high-temperature sensors in an ISO834 fire test. Fire Safety Journal 71 (2015) 332-339

[5] Rinaudo P, Payá-Zaforteza, Calderón PA. A new methodology for the optimal monitoring of temperatures in tunnels during fire events. Tunnelling and Underground Space Technology 52 (2016) 71-84. Doi: 10.1016/j.tust.2015.11.021

[6] Li Chen, Qin Fang, Xiquan Jiang, Zheng Ruan, Jian Hong. Combined effects of high temperature and high strain rate on normal weight concrete. International Journal of Impact Engineering 86 (2015) 40-56

[7] M.L. Romero, A. Espinos, J.M. Portolés, A. Hospitaler, C. Ibañez. Slender doubletube ultra-high strength concrete-filled tubular columns under ambient temperature and fire. Engineering Structures 99 (2015) 536-545.

[8] Kai Xiang, Guo-hui Wang. Experimental Study on Temperature Distribution of Concrete Filled Steel Tube Reinforced Concrete Square Short Columns. Procedia Engineering 71 ( 2014 ) $16-21$

[9] Shu-Yu Fan, Han-Sheng Chiu, Ding-Yi Lin, Alexandra Liao, Kuo-Chih Liao. Percutaneous fiber-optic biosensor for immediate evaluation of chemotherapy efficacy in vivo (Part II): In vitro and in vivo characterization. Sensors and Actuators $222 \mathrm{~B}$. (2016) 579-587

[10] Glišić B, Inaudi D (2007). Fibre Optics Methods for Structural Health Monitoring. Chichester: John Wiley \& Sons Ltd.

[11] Rinaudo P., Paya-Zaforteza I., Calderón P.A., Sales S. Experimental and analytical evaluation of the response time of high temperature fiber optic sensors. Sensors and Actuators A Physical $243(2016)$ 167-174. DOI: 10.1016/j.sna.2016.03.022.

[12] Chen Yang, S Olutunde Oyadiji. Development of two-layer multiple transmitter fibre optic bundle displacement sensor and application in structural health monitoring. Sensors and Actuators A 244 (2016) 1-14. 
[13] David Barrera, Vittoria Finazzi, Joel Villatoro, Salvador Sales, Valerio Pruneri. Packaged Optical Sensors Based on Regenerated Fiber Bragg Gratings for High Temperature Applications. IEEE SENSORS JOURNAL, VOL. 12, NO. 1, JANUARY 2012

[14] Tobias Habisreuther, Tino Elsmann, Zhiwen Pan, Albrecht Graf, Reinhardt Willsch, Markus A. Schmidt. Sapphire fiber Bragg gratings for high temperature and dynamic temperature diagnostics. Applied Thermal Engineering 91 (2015) 860-865.

[15] Y.Tu, Y.H.Qi, S.T.Tu. Fabrication and thermal characteristics of multilayer metalcoated regenerated grating sensors for high-temperature sensing, Smart Mater.Struct. 22 (2013) 75026-75036.

[16] John Canning. Regeneration, regenerated gratings and composite glass properties: the implications for high temperature micro and nano milling and optical sensing. Measurement 79 (2016) 236-249.

[17] Antonio Bueno, Benjamín Torres, David Barrera, Pedro Antonio Calderón, José Manuel Lloris, María José López, Salvador Sales. Optical fiber sensors embedded in concrete for measurement of temperature in a real fire test. Optical Engineering 50(12), 124404 (December 2011).

[18] Rinaudo, P. Estudio del encapsulado de sensores de fibra óptica para la medida de muy altas temperaturas y de pautas para su aplicación en la monitorización de túneles sometidos a fuego. Tesis doctoral. Editorial Universitat Politècnica de València. 2015. doi:10.4995/Thesis/10251/54124.

[19] Majumder M, Gangopadhyay TM, Chakraborty AK. Fibre Bragg gratings in structural health monitoring-present status and applications. Sensors Actuators A 2008;147:150-64.

[20] K.T.V. Grattan, T. Sun, Optical Fiber Sensor Technology: Advanced Applications Bragg Gratings and Distributed Sensors, Springer, 2000.

[21] T.Erdogan, V.Mizrahi, P.J.Lemaire, D.Monroe. Decay of ultraviolet-induced fiber Bragg gratings, J.Appl.Phys. 76 (1994) 73.

[22] J.Canning, K.Sommer, M.Englund, Fibre gratings for high temperature sensor applications, Meas.Sci.Technol.12 (2001) 824-828.

[23] Benjamin Torres, Ignacio Payá-Zaforteza, Pedro A. Calderón, Jose M. Adam. Analysis of the strain transfer in a new FBG sensor for Structural Health Monitoring. Engineering Structures 33 (2011) 539-548.

[24] Moyo P, Brownjohn JMW, Suresh R, Tjin SC. Development of fiber Bragg grating sensors for monitoring civil infrastructure. Eng Struct 2005;27:1828-34.

[25] Barrera D, García R, Sales S, Gasch I, Ivorra S, Giménez E. Application of fiber Bragg grating optic sensors for material characterization. $5^{\circ}$ Reunión Española de Optoelectrónica. Optoel'07. 2007 [in Spanish]. 
Torres-Gorriz B., Paya-Zaforteza, I., Calderon Garcia, P.A., Sales Maicas, S.

New fiber optic sensor for monitoring temperatures in concrete structures during fires

(2017) Sensors and Actuators, A: Physical, 254, pp. 116-125. DOI: 10.1016/j.sna.2016.12.013

[26] Micron Optics, Sensing analysis software ENLIGHT. [Online]. Available: 〈http:// www.micronoptics.com/uploads/library/documents/datasheets/Micron_Optics_ENLIGH T.pdf). [accessed:14.11.15].

[27] Lusas. Lusas Reference Manual. Surrey (UK); 2010.

[28] CEN, Eurocode 2: Design of concrete structures-Part 1-2: General rules-Structural Fire Design. Comité Européen de Normalisation, Brussels, Belgium, 2004. 